\title{
Study on the Suitable Water-Saving Irrigation Technology for Mining Areas in the Northwestern Arid Desert Regions in China
}

\author{
Yanping Liu, Hao Rong, Dan Shan, Zhanqi Liang \\ Institute of Water Resources for Pastoral Area of the Ministry of Water Resources of China, Hohhot, China \\ Email:527402097@qq.com
}

How to cite this paper: Liu, Y. P., Rong, H., Shan, D., \& Liang, Z. Q. (2020). Study on the Suitable Water-Saving Irrigation Technology for Mining Areas in the Northwestern Arid Desert Regions in China. Journal of Geoscience and Environment Protection, 8, 127-133.

https://doi.org/10.4236/gep.2020.810009

Received: September 1, 2020

Accepted: October 13, 2020

Published: October 20, 2020

\begin{abstract}
Water is the key factor to ensure plant survival in the process of ecological restoration in the coal base of China northwest deserts. On the premise of meeting the mine production and living water demands, we should take measures such as dirt wastewater treatment and water-saving irrigation to increase income and reduce expenditure and allocate limited water resources rationally, to provide mining area ecological restoration maximum usable water resources. The mining dump has large slope and thin soil layer and it is easy to produce surface runoff. So it is particularly important to study the irrigation technology needed to satisfy vegetation restoration, on the premise of guaranteeing not to produce surface runoff and the slope stability. In this paper, through field plot test, the suitable irrigation method for mine slope, slope surface soil moisture migration characteristics and slope stability analysis were studied. Results show that three slope irrigation technologies have their own advantages and disadvantages. On the whole, the effect of drip irrigation is the best, micro spray irrigation is the second, infiltrating irrigation is not ideal. The permeability of mine soil slope is very strong, the infiltration rate of the slope direction is the highest, inverse slope infiltration rate is lowest. In the process of irrigation, with the increase of soil moisture content, slope safety factor is the decreased obviously, the whole slope surface soil moisture content is $14 \%$ for the slope stability safety threshold.
\end{abstract}

\section{Keywords}

Mining Areas, Vegetation Restoration, Side Slope, Water-Saving Irrigation, Stability

\section{Introduction}

China is rich in coal resources, and the development of a large number of coal 
mines leads to the fragmentation of the local landscape pattern and damage to the ecosystem, which is the whole process of destruction and pollution to the ecological environment. Further coordination of energy economic development and ecological environment protection is one of the prominent problems in the process of energy development in various regions [Wu et al., 2014; Li \& Jiang, 2004; Yang, 2015]. It is more serious in the northwest arid desert coal base, because of drought, water shortage and heavy damage of the local limited surface water and groundwater resources. Especially a large number of waste dumps formed by discharging the gangue in the process of production, which change the soil mechanical composition and structure, make its poor water conditions, poor soil, low biological activity. In heavy rain, wind and the action of gravity, it is easy to appear new soil and water loss, such as surface erosion, gully erosion, sand surface erosion, subsidence, collapse, landslide, and so on [Guo et al., 2015; Lu et al., 2003; Li \& Wang, 2018]. Therefore, restoration and reconstruction of the vegetation, especially the slope ecology, is an important part of the ecological restoration in mining areas. For the vegetation restoration of the waste dump slope, irrigation is one of the main means to ensure the water needed for the growth and development of vegetation on the slope. It can make up for the lack of atmospheric precipitation and the uneven distribution of water and gas in space, which is conducive to the normal growth of plants and enhance their competitiveness [Liang et al., 2016; Liu et al., 2018; Rong et al., 2018]. Through suitable water-saving irrigation technology research based on vegetation restoration and slope stability, it can satisfy slope vegetation water requirement to the hilt, at the same time, deep seepage and slope surface runoff will not produce. It has an important guiding role to choose suitable way of irrigation, reasonable layout of irrigation, and developing an irrigation system. It has important scientific significance for perfecting our country mining area land reclamation technology system and theory, improving the scientific technology content of coal development ecological restoration and promoting regional scientific and technological progress. It can also provide technical support for ecological security in northwest arid desert coal base.

\section{Testing Program}

The test plot is selected from waste dump slopes with the overlying soil thickness of more than $30 \mathrm{~cm}$. After the slope soil preparation, two different vegetation allocation modes suitable for the local area were set up. At the same time, according to the local water resources, several micro-irrigation technologies including micro-sprinkler irrigation, ground drip irrigation and infiltration irrigation were set up in each area. Adopting comparative tests method, in each irrigation form, making different vegetation allocation modes and different irrigation control indicators for main factors, we set up the experimental plot (Table 1). Each dealing repeats twice. So we built 26 test plots containing control plot. The slope surface area of each test plot is about 50 square meter, that is, the slope is $10 \mathrm{~m}$ 
Table 1. The various experimental plots setting.

\begin{tabular}{|c|c|c|c|c|}
\hline \multirow{2}{*}{$\begin{array}{c}\text { vegetation } \\
\text { allocation mode }\end{array}$} & \multirow[t]{2}{*}{ repeat } & \multirow{2}{*}{$\begin{array}{l}\text { Irrigation } \\
\text { method }\end{array}$} & \multicolumn{2}{|c|}{ irrigation control indicator } \\
\hline & & & W1 (55\% field capacity) & W2 (45\% field capacity) \\
\hline \multirow[t]{7}{*}{$\mathrm{A}_{1}$} & \multirow[t]{3}{*}{1} & sprinkling $(\mathrm{P})$ & PA1W1 & PA1W2 \\
\hline & & drip (D) & DA1W1 & DA1W2 \\
\hline & & sub-irrigation & SA1W1 & SA1W2 \\
\hline & \multirow[t]{3}{*}{2} & sprinkling $(\mathrm{P})$ & RPA1W1 & RPA1W2 \\
\hline & & drip (D) & RDA1W1 & RDA1W2 \\
\hline & & sub-irrigation & RSA1W1 & RSA1W2 \\
\hline & \multicolumn{2}{|c|}{ Contrast $\mathrm{C} 1$ (no irrigation) } & & \\
\hline \multirow[t]{7}{*}{$\mathrm{A}_{2}$} & \multirow[t]{3}{*}{1} & sprinkling $(\mathrm{P})$ & $\mathrm{PA} 2 \mathrm{~W} 1$ & $\mathrm{PA} 2 \mathrm{~W} 2$ \\
\hline & & drip (D) & DA2W1 & DA2W2 \\
\hline & & sub-irrigation & SA2W 1 & SA2W2 \\
\hline & \multirow[t]{3}{*}{2} & sprinkling $(\mathrm{P})$ & RPA2W1 & RPA2W2 \\
\hline & & drip (D) & RDA2W1 & RDA2W2 \\
\hline & & sub-irrigation & RSA2W1 & RSA2W2 \\
\hline & \multicolumn{2}{|c|}{ Contrast C2 (no irrigation) } & & \\
\hline
\end{tabular}

long and $5 \mathrm{~m}$ wide. There are footpaths between the plots with a width of $0.5 \mathrm{~m}$, which are convenient for experimental observation and sampling. Each plot is an independent plot and the ridge above the slope top is designed to keep the ridge from being damaged by runoff and erosion. At the same time, in order to prevent the interpenetration of groundwater with different irrigation methods and reduce the mutual influence among various test treatments, the isolation buffer zone is set in each test plot. Corresponding water isolation measures are taken, that is, the impermeable film is laid in the buffer zone [Yin et al., 2012; Zhou et al., 2016; Zhu, 2016]. Vegetation configuration model A1 is Agropyron cristatum and Melilotus suaveolens Ledeb. Vegetation configuration model A2 is Agropyron cristatum and Caragana korshinskii [Zhang et al., 2017].

\section{Results and Discussion}

\subsection{Characteristics of Soil Water Transport on Slope Surface}

In the case of certain conditions such as dump slope and soil texture are determined, soil moisture dynamic monitoring is carried out with single droplet head as the center, including downslope direction, adverse slope direction, transverse slope direction and vertical direction of soil [Lu et al., 2018]. The experimental observation results show that disturbed soil has strong permeability, and the infiltration rate decreases obviously after settlement, irrigation (or rainfall). Figure 1 shows the change of soil infiltration rate with time in all directions of the slope. It can be seen from the figure that the infiltration rate is the highest in the direction of slope and the lowest in the direction of reverse slope. After $80-100 \mathrm{mi}-$ 
nutes, the stable infiltration rates in the direction of downslope, vertical, transverse and reverse slope are kept at about $0.6 \mathrm{~mm} / \mathrm{min}, 0.8 \mathrm{~mm} / \mathrm{min}, 0.4 \mathrm{~mm} / \mathrm{min}$ and $0.2 \mathrm{~mm} / \mathrm{min}$ respectively.

\subsection{Vegetation Construction Is Suitable for Irrigation}

The purpose of artificial remolded geomorphic irrigation is to restore the vegetation on the slope surface, so the indexes such as vegetation coverage, vegetation height and above biomass can reflect the irrigation benefits in general. As can be seen from Figure 2, under the three irrigation forms, there are significant differences in several growth indicators of vegetation. The three indicators of No. O plot (drip irrigation) are the highest, while $\mathrm{h}$ plot (seepage irrigation) is the lowest. According to the total vegetation growth of the experimental area, among the three irrigation methods for the vegetation restoration of the artificial reshaped geomorphic slope in this area, ground drip irrigation is the most ap-

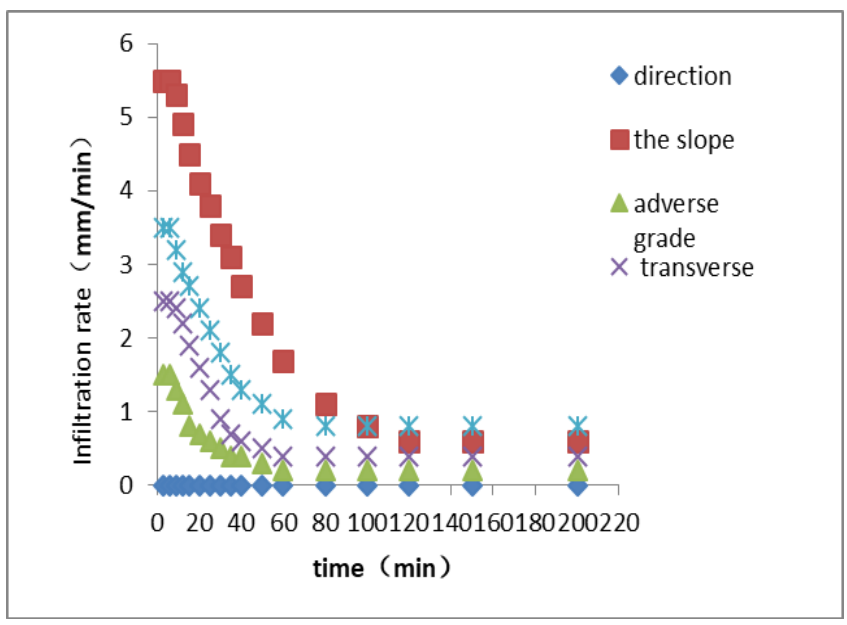

Figure 1. The change of soil infiltration rate.

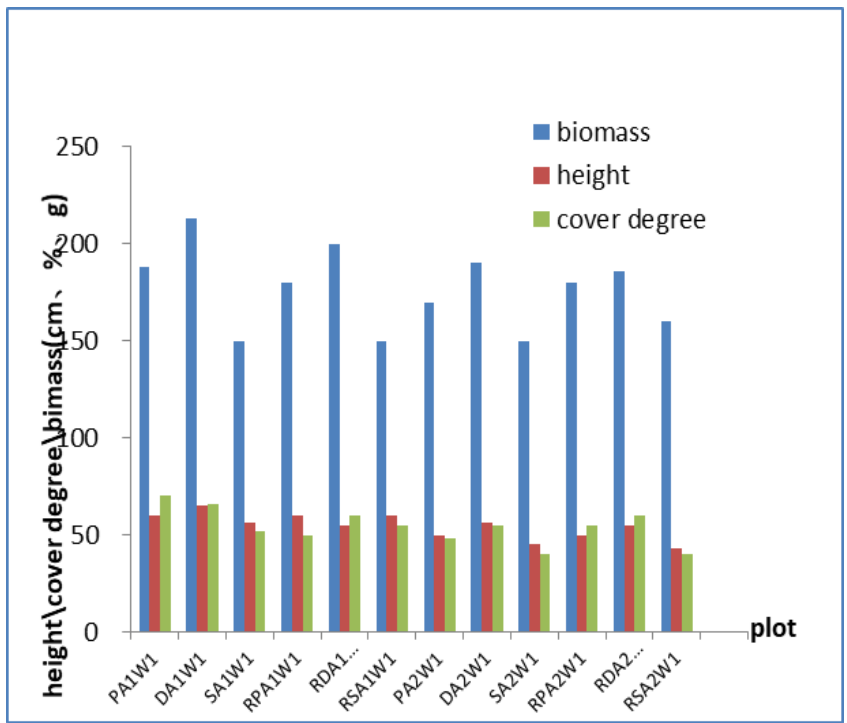

Figure 2. The change process of vegetation growth. 
propriate irrigation method, which has lower investment cost, relatively simple construction operation and obvious water-saving effect.

Under the specific conditions of irrigation water source, remolded geomorphic slope and soil, three irrigation methods were analyzed and evaluated through experimental observation, and their advantages and disadvantages were compared. Water quality requirements, pressure drive, energy consumption, irrigation effect, operation management and protection, and investment cost were mainly selected. Each of the three irrigation forms has its advantages and disadvantages. On the whole, the drip irrigation effect is the best, followed by micro-injection and infiltration irrigation effect is not ideal.

\subsection{Influence of Soil Moisture Content on Slope Stability}

If the external load of the slope remains unchanged, the stability of the slope is mainly affected by the external environment, such as the change of soil water content caused by precipitation, plants on the slope and engineering measures. When the external environment of the dump slope remains unchanged, the shear strength of soil changes, while the stability of the slope changes. Therefore, the change of slope stability is realized by changing the shear strength parameters of soil. In this study, we set different depth of plant roots and soil shear strength parameters under different soil moisture conditions, combined with the actual soil texture, GEO-Slope software is adopted to establish the mine slope model under different soil moisture and plant root depth, based on limit equilibrium theory to calculate the safety factor, then we analyze the changing rule of the slope stability of different plants and different soil water content under irrigation measures.

According to the sequence of observation of dump slope soil water content, the soil moisture content of the slope is generally from $5 \%$ to $29 \%$. When the slope is under natural soil moisture condition, namely under the condition of the soil water content is $5 \%$, the critical slip surface of slope surface is analyzed, the safety coefficient is 1.745 , the most dangerous slip plane is mainly concentrated in the slope body parts, slope stability is best. When the soil moisture content of the slope is from $10 \%$ to $20 \%$, the critical slip surface of the slope is analyzed, and the safety factors are 1.451 and 0.917 respectively. With reference to the safety factor standard, the stability of the slope is at level 3 , and the slope body of the dump slope tends to be unstable. When the soil moisture content is from $25 \%$ to $40 \%$, the calculation results show that the safety factor of the slope of the dump decreases to 0.777 , indicating that the slope is unstable and prone to landslides. However, as the project area is located in arid or semi-arid areas with low annual rainfall, the probability of such extreme events is very small. If some appropriate soil and water conservation measures are deployed, the occurrence of landslides can be prevented. Based on the above analysis, it can be seen that with the increase of soil water content on the slope, the slope safety coefficient significantly decreases, and when the soil water content on the whole slope is 
$14 \%$, it is the safety threshold of slope stability.

According to the soil shear strength corresponding to different water contents, the stability of the slope of the dump was analyzed, and the safety factor was calculated. It was found that there was a power function relationship between the safety factor of the slope and the soil water content and the fitting equation was $y=4.62 x-0.577, R^{2}=0.94$.

\section{Discussion}

For the slope of the mine dump, as the overburden soil layer is generally around $30 \mathrm{~cm}$, the soil moisture content is significantly affected by rainfall and irrigation, and the variation is generally greater on the slope than on the slope. After the implementation of some soil and water conservation projects on the slope, rainfall infiltration can be effectively increased and slope runoff reduced. Meanwhile, with the extension of the restoration years of slope vegetation, vegetation kinetic energy can be reduced and vegetation root system can improve the soil structure on the slope, so as to enhance soil infiltration capacity and further promote slope vegetation restoration.

\section{Conclusion}

In terms of the changes of soil moisture and vegetation growth index, pressure drive, energy consumption, operation management and protection and investment cost, surface drip irrigation is the best way to evaluate vegetation restoration in the slope of coal dump in northwest arid desert area. In the course of irrigation, the slope safety coefficient decreases gradually with the increase of soil water content. When the soil water content of the whole slope is $14 \%$, it is the safety threshold of slope stability. After planting plants, the overall safety coefficient of the slope is increased, that is, the root system of vegetation makes the slope stability significantly improved. Therefore, it is suggested that planting deep root plants, such as alfalfa, on the slope side of the dump can improve the slope stability.

\section{Acknowledgements}

This research was supported by the National Key R \& D Program of China "Eco-security technology for coal mining bases in the Northwestern arid desert regions in China" (2017YFC0504400)— “Studies on the key technologies of water resources protection and comprehensive utilization in mining area"

(2017YFC0504405). This research was also supported by Chinese academy institute director fund project-semi arid ecological fragile area of soil and water conservation under jamming technology research (MK2017J04).

\section{Conflicts of Interest}

The authors declare no conflicts of interest regarding the publication of this paper. 


\section{References}

Guo, J.-Y., He, J-L., Li, J.-R. et al. (2015). Effects of Artificial Remolded Geomorphology on Soil Erosion in Xilin Gol Grassland and Its Control Effect. Journal of Soil and Water Conservation, 29, 56-61.

Li, J.-C., \& Wang, Z. (2018). Exploration of Measures for Soil Erosion Control in the Ecological Environment of Henan Xishan Mining Area. Environment and Development, 5, 49-50.

Li, Y.-G., \& Jiang, G.-M. (2004). Research Progress on Ecological Reconstruction of Abandoned Mine Lands. Acta Ecologica Sinica, 24, 95-100.

Liang, Z.-Q., He, J.-L., Shan, D. et al. (2016). Research on Suitable Irrigation Methods for Artificial Vegetation Restoration of Reclaimed Geomorphic Slope. China Water and Soil Conservation, 7, 57-60.

Liu, Y.-P., Liang, Z.-Q., He, J.-L. et al. (2018b). Research on Water-Saving Irrigation Technology of Slope Vegetation Restoration in Mining Dump. Grassland \& Lawn, 5, 16-21. https://doi.org/10.15377/2410-3624.2018.05.2

Lu, C.-J., Bai, Z.-K., Zhao, J.-K. et al. (2003). Research Progress on Soil Erosion and Soil and Water Conservation in Mining Areas. Journal of Soil and Water Conservation, 17, 85-88.

Lu, G., Liu, Y.-Z., Li, Y.-X. et al. (2018). Spatial Variation Characteristics of Physical Properties of Surface Soil Moisture on Slope of Open-Pit Coal Mine Drainage Dump. Soil Bulletin, 1, 45-49.

Rong, H., He, J.-L., Zhang, X. et al. (2018). Relationship between Aboveground Biomass and Soil Moisture in Different Vegetation Restoration Models of Desert Steppe. Grassland \& Lawn, 5, 71-76.

Wu, G., Wei, D., \& Zhou, Z.-D. (2014). A Review of Ecological Restoration Technology for Large-Scale Coal Base Construction in China. Acta Ecologica Sinica, 34, 2812-2820. https://doi.org/10.5846/stxb201308092052

Yang, Y. (2015). Simple Analysis on the Importance of Environmental Protection in Mining Areas in the New Era. Low-Carbon World, 10, 178-179.

Yin, H., Wang, Q., Shi, S.-L. et al. (2012). Effects of Irrigation and Nitrogen Application on the Yield, Water Use Efficiency and Soil Total Nitrogen Content of Alfalfa in the Second Year of Planting. Grassland \& Lawn, 4, 1-7.

Zhang, Y.-D., Shang, X.-P., Du, F.-L. et al. (2017) Dynamic Changes of Vegetation in Ningxia and Its Response to Precipitation. Journal of Xi'an University of Science and Technology, No. 37.

Zhou, Q., Bao, Z.-Y., Wang, H.-B. et al. (2016). Research on Drip Irrigation System of Silage Maize in Agro-Pastoral Ecotone of Ningxia. Water Saving Irrigation, 9, 112-116.

Zhu, H. (2016). Experimental Study on Irrigation System of Jujube Trees in Old Sand-Pressed Areas of Ningxia. Master's Thesis of Ningxia University. 